DOI: http://dx.doi.org/10.22484/2177-5788.2016v42n1p199-212

\title{
Tradi(visão) e Tradu(visão) em O Último voo do flamingo de Mia Couto
}

Yéo N'gana

Resumo: Se escrever é verter em palavras ideias e fatos, e mesmo até um certo ponto representar o mundo. Mia Couto, por sua vez, contador de histórias, procurou traduzir a vida dos Tizangarenses em "O Último Voo do Flamingo". Este artigo tem como objetivo refletir sobre essa representação do mundo através da passagem da oralidade para a escrita que, em si, é uma tradução intersemiótica influenciada pela visão e pelo mundo do autor.

Palavras-chave: Tradição africana. Tradução. Nomes africanos. Literatura africana. Mia Couto.

\section{Tradi(vision) and Trans(vision) in The Last Flight of the Flamingo by Mia Couto}

Abstract: If writing consists of picturing facts and ideas with words, and even to a certain point representing the world; therefore, Mia Couto as a storyteller, looks to translating Tizangarans' life in The Last Flight of the Flamingo. This article aims at thinking of that passage from orality to writing which is a sort of intersemiotic translation influenced by the author's vision and the world that conditions its production.

Keywords: African tradition. Translation. African names. African literature. Mia Couto. 
N'GANA, Yéo. Tradi(visão) e Tradu(visão) em "O Último voo do flamingo" de Mia Couto.

\section{Mia Couto: vida e obra}

O "Último Voo do Flamingo" foi publicado pela primeira vez no ano 2000 pela editora Editorial Caminho. Antônio Emílio Leite Couto, mais conhecido sob a alcunha Mia Couto, nasceu em Beira, Moçambique, em 1955. Já aos 14 anos, publicou seus primeiros poemas no jornal Notícias da Beira. Em 1972, muda-se para Lourenço Marques, atual Maputo, cursar medicina. Em 1974, opta pelo jornalismo tornando-se repórter e, em seguida, diretor da Agência de Informação de Moçambique (1976), da revista Semanal Tempo (1979-81), do Jornal Notícias (1981-85). Entre prosa e poesia, escreveu mais de 30 livros, entre eles os que constam no quadro 1.

\section{Quadro 1 - Livros de autoria de Mia Couto}

\begin{tabular}{|c|c|c|c|c|}
\hline Gêneros & Títulos & $\begin{array}{c}\text { Anos de } \\
\text { publicação }\end{array}$ & Editoras & Cidades \\
\hline \multirow{4}{*}{ Poesia } & Raiz de Orvalho & 1983 & Cadernos Tempo & Maputo \\
\hline & $\begin{array}{l}\text { Raiz de Orvalho e } \\
\text { outros poemas }\end{array}$ & 1999 & Editorial Caminho & Lisboa \\
\hline & $\begin{array}{l}\text { Idades, Cidades, } \\
\text { Divindades }\end{array}$ & 2007 & $\begin{array}{c}\text { Sociedade Editorial } \\
\text { Ndjira } \\
\text { Editorial Caminho }\end{array}$ & $\begin{array}{l}\text { Maputo } \\
\text { / Lisboa }\end{array}$ \\
\hline & Tradutor de Chuvas & 2011 & Editorial Caminho & Lisboa \\
\hline \multirow{6}{*}{ Contos } & Vozes Anoitecidas & 1986,1987 & $\begin{array}{l}\text { AEMO Editorial } \\
\text { Caminho }\end{array}$ & Maputo / Lisboa \\
\hline & $\begin{array}{c}\text { Cada Homem é uma } \\
\text { Raça }\end{array}$ & 1990 & Editorial Caminho & Lisboa \\
\hline & $\begin{array}{c}\text { Estórias } \\
\text { Abensonhadas } \\
\end{array}$ & 1994 & Editorial Caminho & Lisboa \\
\hline & $\begin{array}{c}\text { Contos do Nascer da } \\
\text { Terra }\end{array}$ & 1997 & Editorial Caminho & Lisboa \\
\hline & $\begin{array}{c}\text { Na Berma de } \\
\text { Nenhuma Estrada }\end{array}$ & 1999 & Editorial Caminho & Lisboa \\
\hline & O Fio das Missangas & 2003 & Editorial Caminho & Lisboa \\
\hline \multirow{3}{*}{ Crônicas } & Cronicando & 1988,1991 & Editorial Caminho & Lisboa \\
\hline & $\begin{array}{c}\text { O País do Queixa } \\
\text { Andar }\end{array}$ & 2003 & $\begin{array}{c}\text { Sociedade Editorial } \\
\text { Ndjira }\end{array}$ & Maputo \\
\hline & $\begin{array}{l}\text { Pensatempos. Textos } \\
\text { de Opinião }\end{array}$ & 2005 & Editorial Caminho & Lisboa \\
\hline
\end{tabular}


N'GANA, Yéo. Tradi(visão) e Tradu(visão) em “O Último voo do flamingo" de Mia Couto.

\begin{tabular}{|c|c|c|c|c|}
\hline & $\begin{array}{l}\text { E se Obama fosse } \\
\text { Africano? e Outras } \\
\text { Interinvenções }\end{array}$ & 2009 & Editorial Caminho & Lisboa \\
\hline \multirow{10}{*}{ Romance } & Terra Sonâmbula & 1992 & Editorial Caminho & Lisboa \\
\hline & $\begin{array}{l}\text { A Varanda do } \\
\text { Frangipani }\end{array}$ & 1996 & Editorial Caminho & Lisboa \\
\hline & Mar Me Quer & 2000 & Editorial Caminho & Lisboa \\
\hline & Vinte e Zinco & 1999 & Editorial Caminho & Lisboa \\
\hline & $\begin{array}{l}\text { O Último Voo do } \\
\text { Flamingo }\end{array}$ & 2000 & Editorial Caminho & Lisboa \\
\hline & $\begin{array}{l}\text { Um Rio Chamado } \\
\text { Tempo, uma Casa } \\
\text { Chamada Terra }\end{array}$ & 2002 & Editorial Caminho & Lisboa \\
\hline & O Outro Pé da Sereia & 2006 & Editorial Caminho & Lisboa \\
\hline & $\begin{array}{l}\text { Venenos de Deus, } \\
\text { Remédios do Diabo }\end{array}$ & 2008 & Editorial Caminho & Lisboa \\
\hline & Jesusalém & 2009 & Editorial Caminho & Lisboa \\
\hline & Vagas e lumes & 2014 & Editorial Caminho & Lisboa \\
\hline \multirow{4}{*}{ Infantil } & O Gato e o Escuro & 2001, 2008 & $\begin{array}{l}\text { Editorial Caminho / } \\
\text { Cia. das Letrinhas }\end{array}$ & $\begin{array}{c}\text { Lisboa / São } \\
\text { Paulo }\end{array}$ \\
\hline & A Chuva Pasmada & 2004 & $\begin{array}{c}\text { Sociedade Editorial } \\
\text { Ndjira }\end{array}$ & Maputo \\
\hline & O beijo da palavrinha & 2006 & $\begin{array}{c}\text { Editora Língua Geral / } \\
\text { Editorial Caminho }\end{array}$ & Lisboa \\
\hline & $\begin{array}{l}\text { O Menino no } \\
\text { Sapatinho }\end{array}$ & 2013 & Editorial Caminho & Lisboa \\
\hline
\end{tabular}

Fonte: Elaboração própria. Elaborado a partir do site oficial do Mia Couto, do Portal da Literatura em português, do site da Lusofonia e da Companhia de Letras, respetivamente disponíveis em:

$<$ http://www.miacouto.org/biografia-bibliografia-e-premiacoes/>.

$<$ http://www.portaldaliteratura.com/autores.php?autor=392>.

$<$ http://www.companhiadasletras.com.br/autor.php?codigo=01846>.

<http://lusofonia.x10.mx/mia.htm>. Acesso em: 10 jan. 2016.

Entre os prêmios recebidos por Couto, pode-se citar: Prêmio Anual de Jornalismo Areosa Pena (1989), Prêmio Vergílio Ferreira (1990), Prêmio Nacional de Ficção da Associação de Escritores Moçambicanos (1995), Prêmio Mário António com o livro O Último Voo do Flamingo (2001), Prêmio União Latina de Literaturas Românicas (2007), Prêmio Passo Fundo Zaffari e Bourbon de Literatura (2007), Prêmio Eduardo Lourenço (2011), Prêmio Camões (2013), Prêmio Internacional Literatura Neustadt (2014). 
N'GANA, Yéo. Tradi(visão) e Tradu(visão) em "O Último voo do flamingo" de Mia Couto.

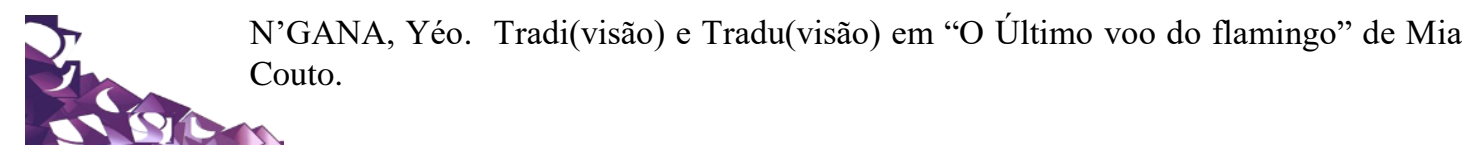

Trata-se em "O Último Voo do Flamingo" das aventuras de Massimo Risi, um inspetor italiano enviado pelas Nações Unidas para investigar repetidos casos estranhos de mortes na vila de Tizangara em Moçambique. Após o fim da guerra, os soldados enviados à vila de Tizangara para manter a paz, começaram a explodir sem nenhuma explicação racional. Nesse trabalho, buscaremos entender a princípio, a cultura Tizangarense por meio da análise de alguns nomes de personagens, e de alguns provérbios usados por Mia Couto. No segundo ponto, refletiremos sobre os desafios de traduzir uma cultura, principalmente a de Tizangara.

\section{Tradi(visão) e a escrita livre ou fala de Tizangara}

A literatura não é inocente, e a sua culpa é justificada por, muitas vezes, forjar realidades. O mundo forjado é vivido pelos personagens como se fosse real (BASTOS, 2001, p.13). Aliás, os nomes na literatura africana desempenham um papel muito importante no delineamento do quadro geral para o desenrolar da estória. É o que definimos por "tradi(visão)", isto é, a concepção ou visão tradicional de uma pessoa, um povo, uma sociedade, sobre outros povos, outras sociedades e sobre o mundo. No presente caso, pode se tratar tanto do texto de partida quanto do texto de chegada. Se o verdadeiro mistério, nessa obra, reside na forma como os fatos acontecem " $\mathrm{Nu}$ e cru, eis o facto: apareceu um pénis decepado em plena Estrada Nacional, à entrada da vila de Tizangara. Era um sexo avulso e avultado" (COUTO, 2005, p. 5); então a opinião pública acerca do acontecido nos deixa ainda mais perplexos, "Em Tizangara só os factos são sobrenaturais. E contrafactos tudo são argumentos" (idem, p.5). Porém, a resolução do problema apresenta um duplo esforço por parte do italiano: de um lado, passar a barreira linguístico-cultural, "eu posso falar e entender. Problema não é a língua. O que eu não entendo é este mundo aqui” (p. 40); e do outro lado, mergulhar na filosofia para descobrir aquele mundo tão longe e perto, certo e incerto, real e visivelmente surreal. O próximo trecho deixa mais evidente o desafio do italiano, 
N'GANA, Yéo. Tradi(visão) e Tradu(visão) em “O Último voo do flamingo" de Mia

Couto.

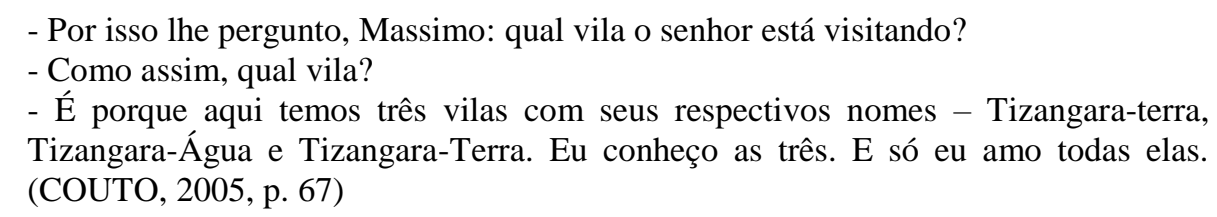

A literatura africana, vista metaforicamente como uma obra, tira sua singularidade das leis da sociedade na qual nasce e se desenvolve (M'BRA, 2012, p. 39). Ao colocar o texto literário na categoria de "texto como produção", sua tradução, segundo Akakuru (2006, p. 2), exige que seja considerada a dinâmica cultural que faz parte da sua produção, junto a ela, uma filosofia de vida pois, "quando nascemos sabemos tudo, mas não lembramos nada. Depois, crescemos, vamos ganhando lembrança e encolhendo sabedoria" (COUTO, 2005, p. 151). A concepção de que os textos literários africanos em línguas europeias já são em si traduções das línguas africanas não só se tornou tradicional, mas também foi fortalecendo cada vez mais a ideia da existência de uma literatura africana pré-colonial, pré-escrita. De um escritor para outro, tanto ao nível epistemológico quanto retórico, a visão do mundo africano domina a instituição literária e determina a escrita (WAMITILA, 1999, p. 34). Os nomes têm uma importância capital na maioria das culturas africanas. Assim, a escolha dos nomes dos personagens feita pelo escritor na sua narrativa é representativa da pertença étnica e da sociedade simbolizada pelo reconhecimento dos costumes na produção ficcional. $\mathrm{O}$ uso, por Mia Couto, de alguns nomes como Sulplício, Ana Deusqueira, Temporinha, e mais outros; chama a atenção. Sulplício é um personagem que sofreu muitos suplícios na vida. O que explicaria talvez o nome Sulplício, a associação de Sul + Suplício deixando o leitor ainda curioso. Será que o autor quis dizer que o personagem passou por todo o suplício do sul de Tizangara? Ana Deusqueira, Ana era tão linda que Deus + queira (quis) que existisse. Temporinha, por sua vez, era uma jovem-velha. Tinha um rosto de velha com um corpo de "moça polpuda e convidativa. [...]só anda no corredor, vive no escuro, desde há séculos" (COUTO, 2005, p. 39). Com ela, o tempo parava. Ela sofreu uma maldição pelos ancestrais por não ter ficado com um homem como vemos aqui: “Tenho duas idades. Mas sou miúda. Nem vinte não tenho. [...] tenho cara de velha porque recebi castigo dos espíritos. [...] Castigaram- 
N’GANA, Yéo. Tradi(visão) e Tradu(visão) em "O Último voo do flamingo" de Mia Couto.

me porque se passaram os tempos sem que nenhum homem provasse da minha carne" (COUTO, 2005, p. 61-62). Segundo Wamitila (1999, p. 38):

Outro aspecto importante dos nomes se relaciona com o conceito de lugar ou de regras. Regra refere às circunstâncias espaço-temporais nas quais a intriga da narrativa ocorreu. Podemos abordar os nomes dos personagens da ficção como indicadores de posição social, econômica e política na qual se encontram. Nesse caso particular, o nome passa a ser indicador de uma qualidade peculiar associada a um personagem de ficção.

Os nomes próprios encontrados ao longo da trama informam sobre a identidade e história do personagem. O nome Temporinha, por exemplo, leva a algumas reflexões, explicações que só o nosso narrador-tradutor nos pode dar, que são culturais. Nas palavras de Couto (2005, p. 62):

Ajudei na explicação. Eu conhecia Temporinha, ela era apenas um pouco mais velha do que eu. Era verdade: ela não aceitara nenhum namoro enquanto moça. Quando deu conta, tinha-se passado o prazo da sua adolescência. Mais que o permitido. E assim desceu sobre ela a punição divina. Numa só noite seu rosto se preencheu de ruga, se perfez nela todo o redesenhar do tempo. Contudo, no restante corpo, ela guardava sua juventude. (Couto, 2005, p. 62)

O mais interessante é que as narrativas africanas, segundo Kwaku (2003, p. 155), se inserem em uma estética onde a violência não se opera somente no decorrer do enredo, mas também na língua da narração. Podemos, então, segundo Wamitila (1999, p. 39), ver a ação de nomear, nesse contexto, como um importante significante ou sema que contribui tanto para a estilística quanto para os isótopos temáticos que o escritor usa consciente ou subconscientemente. Na página oficial do autor, encontra-se a seguinte afirmação:

Mia Couto é um "escritor da terra", escreve e descreve as próprias raízes do mundo, explorando a própria natureza humana na sua relação umbilical com a terra. A sua linguagem extremamente rica e muito fértil em neologismos, confere-lhe um atributo de singular percepção e interpretação da beleza interna das coisas. Cada palavra inventada como que adivinha a secreta natureza daquilo a que se refere, entende-se como se nenhuma outra pudesse ter sido utilizada em seu lugar. As imagens de Mia Couto evocam a intuição de mundos fantásticos e em certa medida um pouco surrealistas, subjacentes ao mundo em que se vive, que envolve de uma ambiência terna e pacífica de sonhos - o mundo vivo das histórias. 
N'GANA, Yéo. Tradi(visão) e Tradu(visão) em "O Último voo do flamingo" de Mia Couto.

Os neologismos de Mia resultam no que Figueiredo (2002) chamou de palavra-mala, que linguísticamente consiste na "síntese disjuntiva" de duas palavras. Elas se imbricam em duas sílabas para formar uma outra. Por exemplo: “O velho Sulplício (Sul + Suplício), sabia ele de sua própria realidade?” (COUTO, 2005, p. 53) “Aquelas ocavidades (oca + cavidades) pareciam recém recentes.” (COUTO, 2005, p. 35). Porém, o que nos interessa aqui, é a palavra. Com base na forma como os africanos manuseiam a língua ao cotidiano, temos a impressão que, na fala oral, as palavras têm vida, mais vivência, são livres e soltas. Elas não têm um sentido fixo e são sujeitas a qualquer interpretação. Durante sua passagem para fala escrita, as palavras se convertem, morrem na fala oral para renascer na escrita (ONG, 2002, p. 14), perdem a sua liberdade em nome da visibilidade. Essas palavras se tornam fracas na carceragem das estruturas estáticas das línguas que as recebem. Mia Couto conta histórias que lhe foram também contadas por alguém. Traduzir nesse caso, aparece como uma (re)re-narração. O que se traduz de uma obra dessa? Qual é a fronteira entre o narrar ou o renarrar e o traduzir em Tizangara?

\section{Tradu(visão) ou tradução de Tizangara}

Para Kwaku (2003), se considerarmos a literatura africana como um instrumento de produção cultural, então é preciso considerar a tradução como uma dimensão essencial dessa literatura. Entendemos por tradu(visão) o processo de tradução da visão de uma sociedade ou uma pessoa tomada a partir de seus referentes (linguísticos, socioculturais, ou extralinguísticos). A tradução desempenha o papel de facilitadora nessa negociação de representatividade, um encontro entre olhares diferentes. Se o tradutor deve trabalhar para manter na sua tradução saber e sabor, que constituem, segundo Akakuru e Chima (2006) os dois polos essenciais da literatura, voltamos a nossa reflexão para esse processo de interpretação dos fatos tanto do ponto de vista linguístico quanto cultural que para nós, carrega uma visão escondida. Para todos os textos literários - de todos os gêneros - o tradutor precisa ter não só uma competência linguística como também uma habilidade comunicativa e estilística. "Escrever, é aplicar o espírito aos problemas colocados pela época em formas linguageiras 
N'GANA, Yéo. Tradi(visão) e Tradu(visão) em "O Último voo do flamingo" de Mia Couto.

específicas feitas de uma inspiração livre, de jogos de palavras, de violências verbais. (AMELA, 2006)"

O crédito dado a Mia Couto, hoje em dia, se justifica de certa forma por causa do jogo de palavras, da criação de neologismos, da nova associação que ele faz dos vocábulos para criar ritmos e rimas, e vivificar os fatos. Por exemplo: "franqueza não é fraqueza" (COUTO, 2005, p. 74), "sexo avulso e avultado [...] mais posto que exposto [...] atropelada ou atropilada" (p. 15), "ficou por ali, manchado e desmanchado" (p. 24), "mudam-se os tempos, desnudam-se as vontades" (p. 36). Entremeada por expressões desse tipo, a obra "O Último Voo do Flamingo" aproxima a prosa poética deixando sua leitura cada vez mais agradável. Porém, a estética do texto africano se complica pelo uso de idoletos e de falas inspiradas pela etnia, com transliterações, com misturas de gêneros diferentes, de arcaísmos originando de vivências pessoais do(s) autor(es). É essa complexa alquimia escondida pela língua africana, de uma visão do mundo cujos segredos são bem guardados e de uma língua europeia longe das realidades do terrão, que faz apelo a conhecimentos transculturais que só podem facilitar a compreensão do texto de partida. Reformulando, isso consiste em entender, antes de tudo, conforme Akakuru e Chima, a dinâmica cultural africana de partida.

Pensar o texto literário africano implica que se entenda a vida, o dia a dia dos povos africanos. A representação dessa vida, às vezes, mística na escrita, é sempre uma interpretação feita pelo escritor que nem sempre a entende. E nesse trecho, como percebe-se na fala do feiticeiro Andorinho: "Não sei, não lhe posso explicar. Teria que falar na minha língua. E é coisa que nem este moço não pode traduzir. Para o que havia que falar não há palavras em nenhuma língua. Só tenho fala para o que invento" (COUTO, 2005, p. 153).

Andorinho nos faz refletir sobre a questão da representatividade. Procurar na língua de outrem expressões ou palavras para descrever uma pessoa ou coisa pressupõe pelo menos o pertencimento de ambos à mesma sociedade. "Só tenho fala para o que invento" é uma marca de diferencial entre os habitats dos dois interlocutores. Como descrever, traduzir ou nomear algo que não existe na outra língua?

É óbvio, observa Akakuru (2006), que a tradução não pode ignorar a natureza do texto a ser re-expresso. É por isso que traduzir um texto literário é sempre um novo desafio para o 
N'GANA, Yéo. Tradi(visão) e Tradu(visão) em "O Último voo do flamingo" de Mia Couto.

tradutor. Pois, é durante o ato tradutório que o signo linguístico perde sua estabilidade e sua rigidez sistêmicas. O signo, em função dos caprichos do autor, não para de se reinventar, de se redefinir no contexto de comunicação. Ao percorrer a literatura pós-colonial africana, temos a impressão de lidar com escritores cujo público-leitor é predefinido por eles já no princípio da obra. Isso, Kourouma (2006, p. 2 apud AKAKURU; CHIMA) mostra-o nesse trecho:

\begin{abstract}
Este livro dirige-se ao africano. Pensei-o em Malinkê e escrevi-o em francês tomando uma liberdade que achei natural com a língua clássica [...] O que fiz então? Simplesmente, me deixei levar pelo meu temperamento destorcendo uma língua clássica que achei rígida demais para que meu pensamento nela, se mova. Traduzi então o malinkê para o francês para encontrar e restituir o ritmo africano. (tradução nossa).
\end{abstract}

Kourouma, em relação a Mia Couto, fica um pouco mais claro na escolha do seu público-leitor. A estrutura das frases e o registro da fala são ferramentas que ele usa bastante para representar e escolher seu público. Não obstante, esse estilo carrega em si uma ideologia, a da restituição da identidade literária a uma África considerada ágrafa, ahistórica e sem literatura. E quando o feiticeiro Andorinho fala com Massimo Risi, disse: "Viver é fácil: até os mortos conseguem. Mas a vida é um peso que precisa ser carregado por todos os viventes. A vida, caro senhor, a vida é um beijo doce em boca amarga [...] Uns não vivem por temer; eu não morro por temer viver" (COUTO, 2005, p. 152-153).

Resolver a questão relativa às mortes só é possível ao entender a vida através da natureza, das coisas nos redores, em resumo, imergir na cultura local. Desse modo, o que há de traduzir aqui é a filosofia de Tizangara, a forma como os habitantes concebem o "viver". Essa visão foi traduzida de novo pelo feiticeiro ao dizer que "o senhor lê o livro, eu leio o chão" (p. 155); o que é a abordagem tradicional africana do ensino. Enquanto os europeus tentavam descobrir o mundo pela ciência, os africanos já tinham se investido em conhecer a natureza, a terra, os rios, os seres vivos e os seres mortos, os visíveis e os invisíveis, o racional e o irracional.

O poder evocativo dessa obra reside na subtileza e no caráter metafórico das falas dos personagens. Embora seja escrito em português quase cada frase leva à uma reflexão por ser 
N'GANA, Yéo. Tradi(visão) e Tradu(visão) em "O Último voo do flamingo" de Mia Couto.

polissêmica. A informação não é explicitamente formulada e exposta ao leitor. Este precisa estar atento e não se deixar complemente submergir pela retórica e a poética que constituem as caraterísticas da escrita de Mia Couto. Pensando na literatura, tanto a obra quanto a tradução não são meras atividades de lazer. Sua elaboração é condicionada, às vezes, até motivada por uma ideologia. Segundo Tymoczko (2013, p. 118), “a ideologia de uma tradução, não reside simplesmente no texto traduzido, mas no modo de expressão e na postura do(a) tradutor(a), bem como na relevência dessa tradução para seu público." Em uma entrevista intitulada "O problema da tradução" no youtube, Mia Couto afirmou que:

Uma boa tradução é como uma tradução poética. Quem está a traduzir tem que ser um
poeta, tem que recriar. Isso é possível também ser feito. Mas, em alguns momentos,
não resolve o que para nós, é quase natural. Sei como é traduzir os títulos dos meus
livros [...] como é que se traduz terras abensonhadas? Como se traduz Mar me quer
por exemplo? Não funciona. (Transcrição nossa
http://www.youtube.com/watch?v=UheAZkKo4D0)

Mia sabe da dificuldade que representa qualquer projeto de tradução da sua produção literária; uma vez que na sua escrita, percebe-se o sotaque africano, o sotaque moçambicano ou melhor, o sotaque da terra como quando Sulplício fala para o tradutor-narrador, "Agora, meu filho, eu já não falo nenhuma língua, falo sotaques. Entende?” (p. 53). Entendemos por sotaque a manifestação fisiológica da história da língua, dos dizeres, das crenças, da filosofia da sociedade na qual se fala. Mas essa diferença há de tornar inferior ou sem valor as obras que a carregam?

\section{Por uma (socio)crítica da literária africana?}

Vários estudos em ciências humanas e sociais, segundo Ntakirutimana (2006), mostraram suficientemente que a oralidade é um dos componentes importantes na formação da identidade comunitária e da identidade individual em si. O universo ficcional revela, então, forças que defendem e veiculam valores antagônicos (M'BRA, 2012, p.41). Essas forças, continua M'bra, são representadas em geral por personagens em busca de valores autênticos e que se deparam com a injustiça de um sistema político, social ou cultural. Se concordamos com 
N'GANA, Yéo. Tradi(visão) e Tradu(visão) em “O Último voo do flamingo" de Mia Couto.

a ideia de que o presente se inspira do passado para construir o futuro; então, as culturas e literaturas tradicionais africanas também podem. Pois, Hampâté Ba (1993, p. 83), afirmava, referindo-se ao contexto africano, que "um conto é a mensagem de ontem destinada para amanhã, transmitida através de hoje".

Do mesmo modo, segundo Ntakirutimana (2006), o escritor pós-colonial vai se inspirar da tradição adaptando a mensagem oral à situação presente. A narrativa (escrita) africana, a princípio, traduzia um realismo que apresentava enredos lineares inspirados da autobiografia. A cativante discussão que opõe oralidade e escrita, minoria e dominante, hegemonia e periferia, é motivada por interesses políticos. Escrever, para Kossi (1998 apud AMELA, 2006, p. 3), é propor múltiplas figurações do mundo. “As narrativas africanas procuram implicitamente reforçar em cada membro do público, a significação da identidade, uma identidade multidimensional ao mesmo tempo individual, comunitária e universal" (NTAKIRUTIMANA, 2006, p. 4). Por isso, avaliar o polo crítico d(ess)a literatura significa não somente interessar-se nos trabalhos de pesquisa, mas também nas questões políticas, sociais e econômicas não declaradas (KEMEDJIO, 1991, p. 125). Com base na trama principalmente com esse trecho:

Fui eu que transcrevi, em português visível, as falas que daqui se seguem. Hoje são vozes que não escuto senão no sangue, como se sua lembrança me surgisse não da memória, mas do fundo do corpo. É o preço de ter presenciado tais sucedências. Na altura dos acontecimentos, eu era o tradutor ao serviço da administração de Tizangara. Assisti a tudo o que aqui se divulga, ouvi confissões, li depoimentos. Coloquei tudo no papel por mando de minha consciência. Fui acusado de mentir, falsear as provas de assassinato. Me condenaram. Que eu tenha mentido, isso não aceito. Mas o que passou só pode ser contado por palavras que ainda não nasceram. Agora, vos conto tudo por ordem de minha única vontade. É que preciso livrar-me destas lembranças como o assassino se livra do corpo da vítima. (COUTO, 2005, p. 9).

Podemos nos situar, nos reconstruir, logo no início, com o contexto social que condicionou a produção da obra e que serviu de pano de fundo para a intriga. A maior parte da literatura pós-colonial teve esse estilo. O que nos interessa, não obstante, é a recepção dessa literatura e o olhar sobre ela. Melone (apud M'BRA, 2012, p. 45) afirma que: 
N'GANA, Yéo. Tradi(visão) e Tradu(visão) em “O Último voo do flamingo" de Mia Couto.

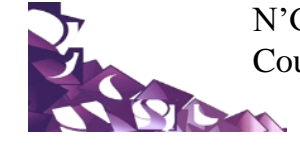

[...] chegou o tempo para que emerja uma crítica literária africana, para apresentar ao público mundial, as obras mais significativas da nossa literatura com base na nossa própria sensibilidade estética, nossa própria avaliação das civilizações negroafricanas, nossa própria visão do destino africano, conforme a originalidade de nosso ritmo, do movimento preocupado da nossa linguagem, e das leis do patrimônio cultural universal. (tradução nossa)

A influência do mercado e o que há de ser o paradigma para as produções literárias africanas sempre alimentaram os debates entre estudiosos. Tymoczko (2013, p. 116) vai além da produção para se interessar no transporte das produções já existentes quando assegurou que:

\begin{abstract}
A ideologia de uma tradução é apenas parcialmente determinada pelo contéudo de um texto de partida - o sujeito e sua representação - mesmo que esse contéudo possa ser, ele mesmo, abertamente político e incrivelmente complicado enquanto ato discursivo, com aspetos locutórios, ilocutórios e perlocutórios do texto de partida, todos contribuindo para dar efeito no contexto de partida.
\end{abstract}

Obviamente, nenhum texto de origem, não digo original ou tradução, é neutro, isento de ideologia. Escrevemos para mostrar algo, passar uma mensagem, apresentar uma vivência ou partilhar uma visão e esperamos, às vezes, uma reação. As ex-colônias, portanto, se encontram em um tipo de dilema por serem obrigadas a produzir nas línguas que herdaram do ex-colonizador; consequentemente nutridas pelo pensamento ou pela visão carregados pela língua. Lembrando, todavia, que a língua é inconcebível sem a cultura, uma vez que influencia muito tanto o estilo e quanto o conteúdo das obras. A esse respeito, Njoh-Mouelle (apud M'BRA, 2012, p. 50) se indigna:

\footnotetext{
Não escrevemos para sermos aplaudidos necessariamente por estrangeiros, mas ao contrário, por os que nos podem entender porque partilham as mesmas condições de existência conosco. Se os aplausos podem vir desses ou daqueles, que isso seja um aditivo. Mas quando só aplaude o exterior e que o interior se cala, é indiscutivelmente o signo de uma falha ou simplesmente o signo de uma alienação sempre lamentável. (tradução nossa).
}

Apesar das exigências do mercado e por meio dele, o projeto dos mais fortes de dominarem, esmagarem os mais fracos, muitos escritores, principalmente os da nova geração, estão cientes de que seguir a tendência é aceitar morrer lentamente, é sacrificar sua civilização, sua identidade e a diversidade. 
N’GANA, Yéo. Tradi(visão) e Tradu(visão) em "O Último voo do flamingo" de Mia Couto.

No limiar de nosso trabalho, é importante lembrar como a questão da cultura permanece complexa. Envolve muitos fatores tanto implícitos quanto explícitos à língua em que se escreve. Percebemos o quão impressionante e subjetiva uma literatura pode ser. A peculiaridade da produção de Mia Couto mostra que nesse mercado global só tem importância a diversidade. É essa diferença que os escritores africanos da nova geração devem procurar manter e alimentar voltando a beber nas suas respectivas culturas seculares ou até milenares. Descobrir e partilhar essa profunda e bem conservada arte, é que há de ser a tarefa de todos. Por isso, nenhuma teoria fora desse contexto nos parece relevante para julgar da sua literaridade.

\section{Referências}

AKAKURU, I. A.; CHIMA, D. C. Réflexion sur la littérature africaine et sa traduction. Translation Journal, Chicago, v. 10, n. 3, 2006. Disponível em: <http://translationjournal.net/journal/37lit.htm>. Acesso em: 11 nov. 2015.

AMELA, Didier. Vers le renouvellement de l'écriture romanesque dans la littérature francophone d'Afrique subsaharienne: la polka de Kossi Efoui. Ethiopiques: revue négro-africaine de littérature et de philosophie, Dakar, n. 77, 2006. Disponível em: <http://ethiopiques.refer.sn/spip.php?article1516>. Acesso em: 26 ago. 2015.

BASTOS, Hermenegildo José. Literatura e colonialismo: rotas da navegação e comércio no fantástico de Murilo Rubião. Brasília: Ed. da UNB, 2001.

COUTO, Mia. Biografia. Disponível em: http://www.miacouto.org/biografia-bibliografia-epremiacoes/. Acesso em: 10 jan. 2016.

COUTO, Mia. Bibliografia. Disponível em:

$<$ http://www.portaldaliteratura.com/autores.php?autor=392>

$<$ http://www.companhiadasletras.com.br/autor.php?codigo $=01846>$

<http://lusofonia.x10.mx/mia.htm>. Acesso em: 10 jan. 2016.

COUTO, Mia. O problema da tradução. Disponível em:

<http://www.youtube.com/watch?v=UheAZkKo4D0>. Acesso em: 9 jan. 2016.

COUTO, Mia. O último voo do Flamingo. São Paulo: Cia das Letras, 2005.

FIGUEIREDO, Olívia Maria. O ficcionário de O Último Voo do Flamingo de Mia Couto. Revista da Faculdade de Letras: Línguas e Literaturas, Porto, n. 19, p. 521-538, 2002.

HAMPATE BA, Amadou. Petit bodiel. Abidjan: Nouvelles Editions Ivoiriennes, 1993. 
N’GANA, Yéo. Tradi(visão) e Tradu(visão) em "O Último voo do flamingo" de Mia Couto.

KWAKU, A. G. The African writer as translator: writing African Languages through French. Journal of African Cultural Studies, London, v. 1, n. 2, 2003. Disponível em:

<http://www.jstor.org/stable/3559466>. Acesso em: 23 ago. 2015.

KEMEDJIO, Cilas. L. Mateso: La littérature africaine et sa critique. Etudes littéraires, Québec, v. 24, n. 2, 1991. Disponível em: <https://www.erudit.org/revue/etudlitt/1991/v24/n2/500973ar.pdf $\geq$. Acesso em: 27 ago. 2015.

M'BRA, Kouakou. La littérature africaine et ses lieux d'insoumission. Revue Baobab, Abidjan: n.11, 2012. Disponível em: < http://www.revuebaobab.org/content/view/225/33/>. Acesso em: 2 set. 2015.

NTAKIRUTIMANA, Jean. De la valeur éducative du genre narratif dans les sociétés africaines traditionnelles. Ethiopiques Littérature, philosophie et art, Dakar, n. 77, 2006. Disponível em: <http://ethiopiques.refer.sn/spip.php?article1524>. Acesso em: 26 ago. 2015.

ONG, Walter J. Orality and literacy: the technologizing of the word. London: Routledge, 2002.

TYMOCZKO, Maria. Ideologia e posição do tradutor. In: BLUME, Rosvitha Friesen; PETERLE, Patricia (Org.). Tradução e relações de poder. Tubarão: Copiart, 2013.

WAMITILA, Kyallo W. What's in a name: towards literary onomastics in kiswahili literature. AAP, Bayreuth: n. 60, 1999. Disponível em: <https://profiles.uonbi.ac.ke/wadi/publications/whats-nametowards-literary-onomastics-kiswahili-literature \. Acesso em: 15 set. 2015.

N'gana, Yéo - Universidade Federal de Santa Catarina | Florianópolis | Santa Catarina. Contato: nganayeo@gmail.com 